\title{
An Estimation Method of Pore Structure and Mineral Moduli Based on Kuster-Toksöz (KT) Model and Biot's Coefficient
}

\author{
Da PENG, Cheng YIN, Hu ZHAO, and Wei LIU \\ Southwest Petroleum University, Sichuan Province Key Laboratory \\ of Natural Gas Geology, School of Geoscience and Technology,Chengdu, China; \\ e-mail: pengda2012@163.com
}

\begin{abstract}
Pore structure and mineral matrix elastic moduli are indispensable in rock physics models. We propose an estimation method of pore structure and mineral moduli based on Kuster-Toksöz model and Biot's coefficient. In this technique, pore aspect ratios of five different scales from 100 to $10^{-4}$ are considered, Biot's coefficient is used to determine bounds of mineral moduli, and an estimation procedure combined with simulated annealing (SA) algorithm to handle real logs or laboratory measurements is developed. The proposed method is applied to parameter estimations on 28 sandstone samples, the properties of which have been measured in lab. The water saturated data are used for estimating pore structure and mineral moduli, and the oil saturated data are used for testing these estimated parameters through fluid substitution in Kuster-Toksöz model. We then compare fluid substitution results with lab measurements and find that relative errors of $\mathrm{P}$-wave and $\mathrm{S}$-wave velocities are all less than $5 \%$, which indicates that the estimation results are accurate.
\end{abstract}

Key words: rock physics, Kuster-Toksöz model, mineral matrix moduli, pore structure, pore aspect ratios spectrum.

Ownership: Institute of Geophysics, Polish Academy of Sciences;

(c) 2016 Peng et al. This is an open access article distributed under the Creative Commons Attribution-NonCommercial-NoDerivs license,

http://creativecommons.org/licenses/by-nc-nd/3.0/. 


\section{INTRODUCTION}

Reservoir rocks consist of a variety of components, such as minerals, clays, cements, pores, pore fluids, etc. Rock physics models can be used to establish relationships of these physical parameters and dynamic elastic moduli of rocks. Consequently, they can bridge seismic attributes with reservoir parameters. The Gassmann model (Gassmann 1951) is a very useful tool to build these relationships by means of fluid substitution. It considers the effects of mineral components, pore fluids, porosity, and dry rock elastic moduli, and seismic velocities. The Gassmann model assumes well connected pores with no isolated pores. The inclusion model (Ament 1953, Eshelby 1957, Walsh 1965, Wu 1966, Mori and Tanaka 1973, O'Connell and Budiansky 1974, Berryman 1980, Zimmerman 1984) can be used to construct relationships between pore microstructure parameters and dynamic elastic moduli of rocks. The Kuster-Toksöz (KT) model (Kuster and Toksöz 1974), differential effective medium (DEM) model (Cleary et al. 1980, Norris et al. 1985, Zimmerman 1991), and self-consistent (SC) model (Budiansky 1965, Hill 1965) are often used to analyze effects of pore shapes and percentages of pore aspect ratios on dynamic elastic moduli of rocks and seismic velocities. Rock physics models have many different parameters, such as lithology, clay content, porosity, fluid saturation, mineral matrix moduli, pore aspect ratio spectrum, etc. If these parameters are unknown or given incorrectly, rock physics models cannot implement fluid substitution and predict velocities. Therefore, many researchers have investigated estimation methods to estimate these rock physics parameters.

Tran proposed a modified DEM velocity estimation scheme to estimate pore aspect ratio spectra on a suite of Berea sandstones (Tran 2008). Lev Vernik developed empirical relations for estimating pore-shape factors based on the noninteraction approximation with the Mori-Tanaka model (Vernik and Kacanov 2010). Jensen gave a procedure for estimating the mineral elastic moduli of smectite and kaolinite by using Hashin-Shtrikman upper and lower bounds (Jensen et al. 2011). Lin et al. developed an estimation method for self-adapting mineral matrix bulk moduli based on Gassmann theory (Lin et al. 2011). Spikes applied the self-consistent model to estimation of pore aspect ratios for both patchy and uniform fluid saturation in Haynesville Shale. Bakhorji used the DEM model which has a set of pores with low aspect ratios to estimate elastic properties in low porosity sandstones (Bakhorji 2012). Mavko and Saxena developed an embedded-bound method for estimating the change in dynamic bulk moduli upon substitution of solid in the pore space (Mavko and Saxena 2013). Johansen proposed an inverse rock physics modeling (IRPM) strategy for estimation of lithology and other rock properties from seismic data (Johansen et al. 2013). Mikhail Markov pro- 
posed a novel approach for simulating the elastic properties of porous rocks based on the generalized differential effective medium (GDEM) method (Markov et al. 2013).

The above estimation methods, however, cannot estimate mineral matrix elastic moduli and pore structure simultaneously. In this paper, we propose an estimation method to estimate pore structure and mineral moduli simultaneously based on the KT model and Biot's coefficient. The technique is tested on 28 sandstone samples with high and low porosities. Firstly, pore aspect ratios of five different scales are constructed: $10^{0}, N_{1} \times 10^{-1}, N_{2} \times 10^{-2}, N_{3} \times 10^{-3}$, and $N_{4} \times 10^{-4}$, and the initial values of $N_{1}, N_{2}, N_{3}$, and $N_{4}$ are randomly generated. Secondly, Biot's coefficient is used to build relationships among different rock elastic moduli; upper and lower bounds of mineral matrix moduli for all sandstone samples are calculated; and the initial estimated values within the bounds are randomly generated. Finally, simulated annealing (SA), global optimization algorithm (Metropolis et al. 1953), is used to optimize the randomly generated rock physics parameters until the minimum of two objective functions are reached and the generated parameters remain unchangeable. This leads to estimation of pore structure and mineral moduli of 28 sandstone samples. Comparison of relative errors of P-wave and S-wave velocities between fluid substitution results with lab measurements shows that the relative errors are all less than 5\%. Moreover, when only having log data (porosity, bulk density, saturation, P-wave and S-wave velocities), this new estimation method can be directly used to estimate pore aspect ratios spectrum and mineral matrix elastic moduli accurately.

\subsection{KT model and pore structure}

The KT model bridges porosity, pore shape, mineral moduli, and fluid inclusion moduli with P-wave and S-wave velocities. This model assumes a low concentration of the inclusions, and also assumes that all pores are ellipsoidal, which can be described with pore aspect ratios. This parameter is defined by the ratio of short and long axes of the inclusion. The KT model can be written as:

$$
\begin{gathered}
\left(K_{s a t}-K_{m a}\right) \frac{\left(K_{m a}+\frac{4}{3} \mu_{m a}\right)}{\left(K_{s a t}+\frac{4}{3} \mu_{m a}\right)}=\sum_{i=1}^{N} c_{i}\left(K_{i}-K_{m a}\right) P^{m i} \\
\left(\mu_{s a t}-\mu_{m a}\right) \frac{\left(\mu_{m a}+\frac{4}{3} \zeta_{m a}\right)}{\left(\mu_{s a t}+\frac{4}{3} \zeta_{m a}\right)}=\sum_{i=1}^{N} c_{i}\left(\mu_{i}-\mu_{m a}\right) Q^{m i}
\end{gathered}
$$




$$
\begin{gathered}
\zeta_{m a}=\frac{\mu_{m a}}{6} \frac{9 K_{m a}+8 \mu_{m a}}{K_{m a}+2 \mu_{m a}} \\
\varphi=\sum_{i=1}^{N} c_{i}
\end{gathered}
$$

In Eqs. 1-4, $K_{i}$ and $\mu_{i}$, respectively, are bulk moduli and shear moduli of $i$-th fluid inclusion, and $K_{\text {sat }}$ and $\mu_{\text {sat }}$, respectively, are saturated bulk moduli and saturated shear moduli. $c_{i}$ is the volume fraction of $i$-th inclusion, and $\varphi$ is the porosity. $P^{m i}$ and $Q^{m i}$ are strain concentration coefficients when adding $i$-th inclusion in mineral matrix (see Appendix). The coefficients are functions of mineral matrix elastic moduli, $K_{m a}$ and $\mu_{m a}$, and aspect ratio. Coefficients $P^{m i}$ and $Q^{m i}$ can be calculated by Wu's arbitrary aspect ratio (Wu 1966) and Berryman's 3D special pore types (Berryman 1995).

The spectrum of pore aspect ratios is the most important parameter in the KT model. Some researchers have studied the spectra of sandstones, limestones, and granites through electron microscope scanning measurements (Timur et al. 1971, Sprunt and Brace 1974, Hadley 1975). Table 1 lists pore aspect ratio spectra of some typical sandstone samples by using SEM electron scanning results (Toksöz et al. 1979). In Table 1, $\alpha$ is pore aspect ratio, $c(\alpha)$ is the volume fraction of the pore aspect ratio.

Table 1 shows results assuming that there are pore aspect ratios of five different scales for sandstone samples: $10^{0}, N_{1} \times 10^{-1}, N_{2} \times 10^{-2}, N_{3} \times 10^{-3}$ and

Table 1

The spectrum of pore aspect ratios of some typical sandstone samples

(Toksöz et al. 1976)

\begin{tabular}{|c|c|c|c|c|c|c|c|c|c|c|c|}
\hline Name & \multicolumn{7}{|c|}{ The spectrum of pore aspect ratios } & \multirow{2}{*}{ Porosity } \\
\hline $\begin{array}{c}\text { Boise } \\
\text { sand- } \\
\text { stone }\end{array}$ & $\alpha$ & 1 & $1 \mathrm{E}-1$ & $3.5 \mathrm{E}-3$ & $2.8 \mathrm{E}-3$ & $2.1 \mathrm{E}-3$ & $1.7 \mathrm{E}-3$ & $1.3 \mathrm{E}-3$ & $9 \mathrm{E}-4$ & $5 \mathrm{E}-4$ & \multirow{2}{*}{0.25} \\
\cline { 2 - 12 } & $1.877 \mathrm{E}-1$ & $6.2 \mathrm{E}-2$ & $3.7 \mathrm{E}-5$ & $6.1 \mathrm{E}-5$ & $6.4 \mathrm{E}-5$ & $1.4 \mathrm{E}-4$ & $1.1 \mathrm{E}-4$ & $8.5 \mathrm{E}-5$ & $6.2 \mathrm{E}-5$ & \\
\hline $\begin{array}{c}\text { Berea } \\
\text { sand- } \\
\text { stone }\end{array}$ & $\alpha$ & 1 & $1 \mathrm{E}-1$ & $1 \mathrm{E}-2$ & $1.7 \mathrm{E}-3$ & $1.4 \mathrm{E}-3$ & $1 \mathrm{E}-3$ & $6 \mathrm{E}-4$ & $3 \mathrm{E}-4$ & - & \\
\cline { 2 - 10 } & $c(\alpha)$ & $1.399 \mathrm{E}-1$ & $2.2 \mathrm{E}-2$ & $3.7 \mathrm{E}-4$ & $1.4 \mathrm{E}-4$ & $1.4 \mathrm{E}-4$ & $1.6 \mathrm{E}-4$ & $1.3 \mathrm{E}-4$ & $1.1 \mathrm{E}-4$ & - & 0.163 \\
\hline $\begin{array}{c}\text { Navajo } \\
\text { sand- } \\
\text { stone }\end{array}$ & $\alpha$ & 1 & $1 \mathrm{E}-1$ & $1 \mathrm{E}-2$ & $3.5 \mathrm{E}-3$ & $2.8 \mathrm{E}-3$ & $2.1 \mathrm{E}-3$ & $1.6 \mathrm{E}-3$ & $1.2 \mathrm{E}-3$ & $9 \mathrm{E}-4$ & \\
\cline { 2 - 10 } & $1.416 \mathrm{E}-1$ & $2.1 \mathrm{E}-2$ & $2.4 \mathrm{E}-4$ & $1.4 \mathrm{E}-4$ & $2 \mathrm{E}-4$ & $1.5 \mathrm{E}-4$ & $1.8 \mathrm{E}-4$ & $1.4 \mathrm{E}-4$ & $6.5 \mathrm{E}-5$ & 0.1614 \\
\hline
\end{tabular}


$N_{4} \times 10^{-4}\left(N_{1}, N_{2}, N_{3}\right.$, and $N_{4}$ are positive integers which are less than or equal to 10). We use these five pore aspect ratios to describe the pore structure in sandstones. Specifically, $\alpha=10^{\circ}$ represents a spherical pore, which is not closed under pressure. $\alpha=N_{1} \times 10^{-1}$ is an intergranular pore. $\alpha=N_{2} \times 10^{-2}$, $\alpha=N_{3} \times 10^{-3}$, and $\alpha=N_{4} \times 10^{-4}$ are crack pores, which are easily closed under pressure. For example, at $P_{d}=500$ bars, all crack pores with aspect ratios smaller than 0.01 are closed (Toksöz et al. 1976).

Table 1 also shows that different pore aspect ratios have different volume fraction values. The crack pores only take a very small part of pore structure (less than $1 \%$ in each sandstone). These crack pores are indispensable, because the effect of lithological and porosity variations is minimal compared to the effect of the shape and size of crack pores (Kuster and Toksöz 1974, Anselmetti and Eberli 1999, Saleh and Castagna 2004). A low porosity rock may have more flat pores with low aspect ratios, while a high porosity rock may have more spherical pores with high aspect ratios (Wang 2001).

\subsection{Biot's coefficient and mineral moduli}

In rock physics models, the mineral matrix elastic moduli are essential. Although they can be calculated by Voigt-Reuss-Hill (VRH) averaging (Hill 1952) or Hashin-Shtrikman (HS) averaging (Hashin and Shtrikman 1963), mineral components and their percentages must be known firstly through rock thin section analysis. However, the rock thin section results have some problems:

1) There are a large number of mineral components in rocks. The thin section analysis can only provide contents of the main components. Mineral components with low concentrations cannot be observed. However, these minerals may have large elastic moduli that have significant effects on the overall responses of seismic signals.

2) The thin section analysis gives the average percentages of minerals in the samples. If the results of some mineral components have errors, the VRH averaging will fail.

3) Mineral matrix elastic moduli can be affected by diagenesis, formation pressure, temperature, and lithology. It's not always appropriate to refer and use elastic modulus of a mineral component from Mavko (Mavko 1998).

4) Sometimes, it is prone to have errors and abnormal results due to relaxed protocols in lab.

Therefore, an effective and accurate method for estimating mineral matrix elastic moduli is needed. In this paper, we use Biot's coefficient which had been discussed by Krief et al. (1990) and Nur et al. (1998). By building relations between different rock elastic moduli, the upper and lower bounds 
of mineral matrix bulk modulus and mineral matrix shear modulus can be obtained.

Krief et al. (1990) used the sandstone data of Raymer et al. (1980) to find an empirical relation for Biot's coefficient versus porosity:

$$
\begin{aligned}
K_{d r y} & =K_{m a}(1-\varphi)^{(3 /(1-\varphi))} \\
\mu_{d r y} & =\mu_{m a}(1-\varphi)^{(3 /(1-\varphi))}
\end{aligned}
$$

These two equations are then transformed:

$$
\begin{aligned}
K_{m a} & =K_{d r y}(1-\varphi)^{(3 /(\varphi-1))} \\
\mu_{m a} & =\mu_{d r y}(1-\varphi)^{(3 /(\varphi-1))}
\end{aligned}
$$

In rock physics, there are two general relations between mineral matrix elastic moduli and rock elastic moduli:

$$
\begin{gathered}
K_{m a}>K_{s a t}>\mu_{d r y} \\
\mu_{m a}>\mu_{s a t}
\end{gathered}
$$

Thus, when knowing porosity, dynamic rock bulk moduli and shear moduli of saturated sandstones, and using Eqs. 7-10, we get the upper and lower bounds for mineral matrix elastic moduli:

$$
\begin{gathered}
K_{s a t}<K_{m a}=K_{d r y}(1-\varphi)^{(3 /(\varphi-1))}<K_{s a t}(1-\varphi)^{(3 /(\varphi-1))} \\
\mu_{s a t}<\mu_{m a}=\mu_{d r y}(1-\varphi)^{(3 /(\varphi-1))}<K_{s a t}(1-\varphi)^{(3 /(\varphi-1))}
\end{gathered}
$$

And these two equations are simplified to:

$$
\begin{gathered}
K_{\text {sat }}<K_{m a}<K_{\text {sat }}(1-\varphi)^{(3 /(\varphi-1))} \\
\mu_{\text {sat }}<\mu_{\text {ma }}<K_{\text {sat }}(1-\varphi)^{(3 /(\varphi-1))}
\end{gathered}
$$

\subsection{Objective function in SA}

The upper and lower bounds only can limit the variation ranges of mineral matrix elastic moduli, but cannot give specific values. Therefore, in this paper, SA method is used to obtain the specific values within the upper and lower bounds of the mineral moduli. To perform the SA calculations, proper objective functions are required. In this new estimation method, the two objective functions can be defined by:

$$
\Delta f_{1}=\frac{\left|K_{\text {sat }}^{\text {obs }}-K_{\text {sat }}^{K T}\right|}{K_{\text {sat }}^{\text {obs }}} \leq 1 \%
$$




$$
\Delta f_{2}=\frac{\left|\mu_{s a t}^{o b s}-\mu_{s a t}^{K T}\right|}{\mu_{\text {sat }}^{o b s}} \leq 1 \%
$$

where $\Delta f_{1}$ is the objective function for mineral matrix bulk moduli while $\Delta f_{2}$ is for mineral matrix shear moduli. $K_{s a t}^{o b s}$ and $\mu_{s a t}^{o b s}$ are bulk moduli and shear moduli, respectively, of the observed data. $K_{\text {sat }}^{K T}$ and $\mu_{\text {sat }}^{K T}$ are bulk moduli and shear moduli, respectively, of the KT model calculation results. The objective functions for both mineral bulk moduli and shear moduli must be less than $1 \%$ in order to obtain high precision rock physics parameters in the estimation.

\subsection{Estimation procedure}

Estimating the bulk and shear moduli and pore aspect ratio distribution from velocity and porosity measurements is an underdetermined problem; we solve this problem by implementing a simulated annealing (SA) procedure. The execution of this estimation method consist of three steps (Fig. 1):

Step 1: Input P-wave velocity $v_{p}^{o b s}, \mathrm{~S}$-wave velocity $v_{s}^{o b s}$, water saturation $s_{w}^{o b s}$, bulk density $\rho$, and porosity $\varphi$ from laboratory data or $\log$ data.

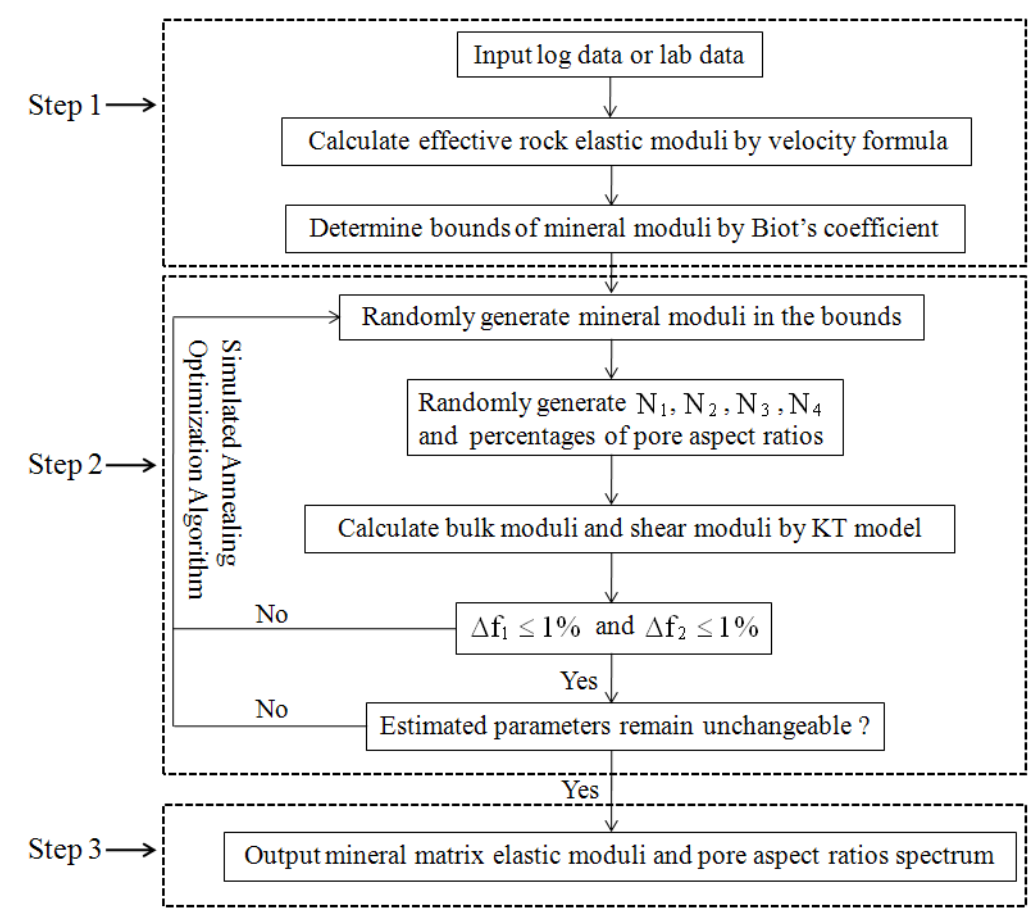

Fig. 1. Estimation procedures of this new estimation method. 
Calculate dynamic rock bulk modulus $K_{\text {sat }}^{o b s}$ and shear modulus $\mu_{\text {sat }}^{o b s}$ of saturated sandstones by velocity formula. And then determine bounds of mineral matrix bulk modulus and shear modulus by using Eqs. 13 and 14 .

Step 2: Randomly generate $K_{m a}$ and $\mu_{m a}$ within the bounds and randomly generate $N_{1}, N_{2}, N_{3}, N_{4}$, and percentages of pore aspect ratios: $\mathrm{c}_{1}, \mathrm{c}_{2}, \mathrm{c}_{3}, \mathrm{c}_{4}$, $\mathrm{c}_{5}$. Use these randomly generated values in KT model to calculate bulk and shear moduli of rock samples. Then compare the calculated results of the rock elastic moduli with lab data and apply SA algorithm to minimize the relative errors to less than $1 \%$ by optimizing the corresponding two objective functions $\Delta f_{1}$ and $\Delta f_{2}$. And judge whether the estimated parameters (mineral moduli and pore aspect ratios spectrum) remain unchangeable or not in the SA iteration process.

Step 3: Repeatedly implement step 2, until the two objective functions reach the minimums (less than 1\%) and the estimated parameters remain unchangeable. Finally, output the estimated parameters: pore aspect ratios spectrum and mineral matrix bulk moduli and shear moduli.

\section{EXPERIMENTAL RESULTS}

In order to validate this new estimation method, 28 sandstones core samples from a depth of $1446 \mathrm{~m}$ to $3496 \mathrm{~m}$ are used in simulations. The KT model assumes a low concentration of the inclusions, and our thin section identification results showed that the assumption is met for the experimental sandstones core samples. The experimental measurement procedure of these 28 sandstones core samples includes preparation, washing oil, drying, porosity measurement under pressure at $1.72 \mathrm{MPa}$, complete water and oil saturation, bulk density measurement (complete water and oil saturated conditions), Pwave velocity and S-wave velocity measurements (complete water and oil saturated conditions). The measurement was processed under the simulated formation temperature and pressure, and the results are shown in Fig. 2.

Figure 2a shows that the porosities of these 28 sandstone samples are from $1.96 \%$ to $22.42 \%$. Thus, we can differentiate these sandstone samples between intermediate-low porosity samples (porosity less than $12.36 \%$ ) and intermediate-high porosity samples (porosity greater than $12.36 \%$ ). Figure $2 \mathrm{~b}$ shows that the densities of these 28 sandstone samples are from $2.1 \mathrm{~g} / \mathrm{cm} 3$ to $2.7 \mathrm{~g} / \mathrm{cm} 3$, and the water saturated data are larger than the oil saturated data. Figure $2 \mathrm{c}$ shows that the $\mathrm{P}$-wave velocities of these 28 sandstone samples are from $3500 \mathrm{~m} / \mathrm{s}$ to $6000 \mathrm{~m} / \mathrm{s}$, and the water saturated data are larger than the oil saturated data. Figure $2 \mathrm{~d}$ shows that the $\mathrm{S}$-wave velocities of these 28 sandstone samples are from $2000 \mathrm{~m} / \mathrm{s}$ to $3500 \mathrm{~m} / \mathrm{s}$, and the water saturated data are larger than the oil saturated data. 
a)

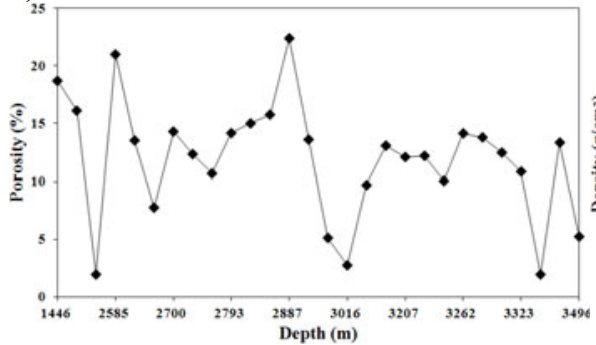

c)

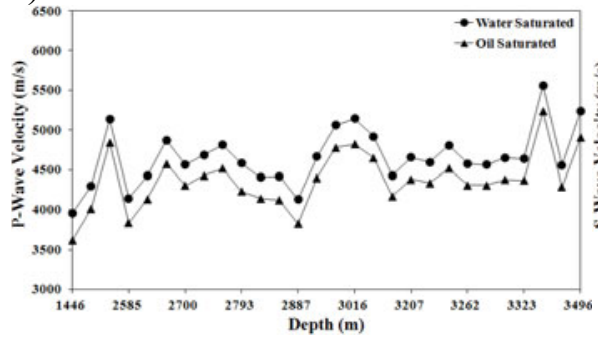

b)

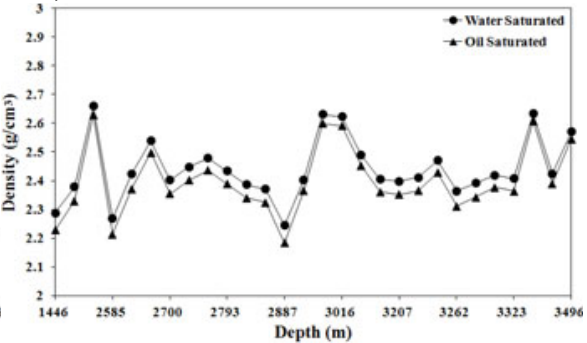

d)

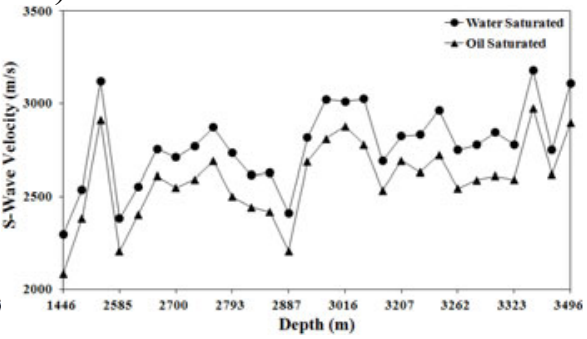

Fig. 2. Measured data of 28 sandstone samples under high pressure (pore pressure at 1.72 $\mathrm{MPa}$ and $68.95 \mathrm{MPa}$ for porosity, bulk density and velocity measurements) and complete water and oil saturated conditions: (a) porosity, (b) density, (c) P-wave velocity (frequency at $0.7 \mathrm{MHz}$ ), (d) S-wave velocity (frequency at $0.2 \mathrm{MHz}$ ). Round line is water saturated data, triangle line is oil saturated data.

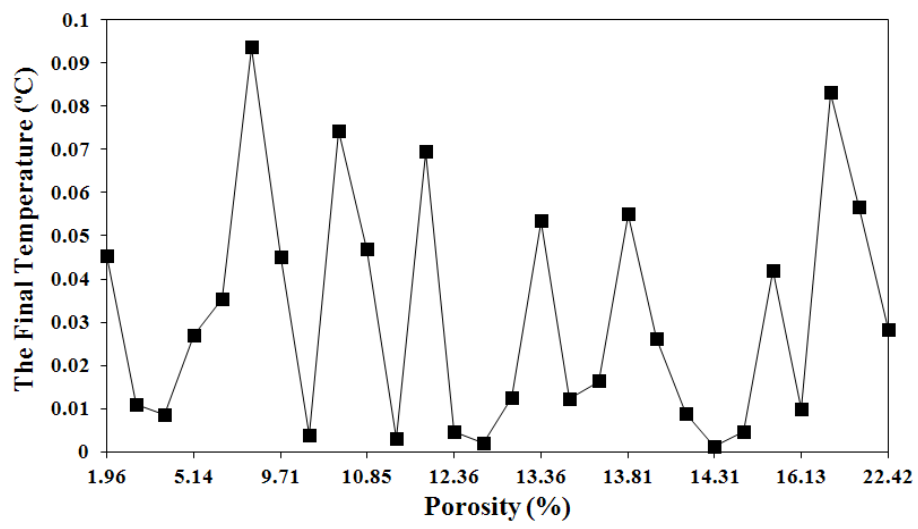

Fig. 3. The final temperature of every iteration process in the estimation procedures of 28 sandstone samples' parameters. In SA optimization algorithm, the initial temperature and the stop temperature of every iteration process respectively are $2000^{\circ} \mathrm{C}$ and $0.001^{\circ} \mathrm{C}$, and the cooling factor is 0.99 .

In $\mathrm{SA}$ optimization algorithm, the initial temperature and the stop temperature of every iteration process, respectively, are $2000^{\circ} \mathrm{C}$ and $0.001^{\circ} \mathrm{C}$, and 
the cooling factor is 0.99 , which ensure enough iteration time (the maximum iteration time is 1443) in the estimation procedures. In every iteration process, when the two objective functions are both less than $1 \%$ and the estimated parameters remain unchangeable, the final temperature in SA is recorded. Figure 3 is the final temperature of every iteration process in the estimation procedures of 28 sandstone samples' parameters. Figure 3 shows that all samples' final temperatures are less than 0.1 (iteration time is 985), and 9 samples' final temperatures are less than 0.01 (iteration time is 1215). This indicates that the final temperatures of every iteration process in the estimation are stable, and SA optimization algorithm is effective.

Figure 4 presents the calculated upper and lower bounds of mineral matrix bulk moduli, mineral matrix shear moduli and the corresponding estimated results. All estimated results are between the upper bounds and lower bounds while a few overlap with the bounds, and the bounds of shear moduli are greater than those of bulk moduli. The mineral elastic moduli are related to the mineralogy of samples, and from Figure 4 we can learn that the mineral constituent of our sandstone samples is various, and there is no clean sandstone sample.

Note that out of 13 samples with porosity less than $12.36 \%$, only for 6 samples the mineral shear moduli are greater than the mineral bulk modulus. In addition, among 15 samples with porosity greater than $12.36 \%$, only 6 samples' mineral shear moduli are greater than mineral bulk moduli. Therefore, for mineral matrix of this sandstone reservoir, bulk moduli are generally greater than shear moduli.

Specifically, for the 13 intermediate-low porosity samples (porosity less than $12.36 \%$ ), the estimated results of bulk moduli are from $26.5 \mathrm{GPa}$ to $45.9 \mathrm{GPa}$, and the estimated results of shear moduli are from $27.8 \mathrm{GPa}$ to 40.4GPa For the 15 intermediate-high porosity samples (porosity greater

a)

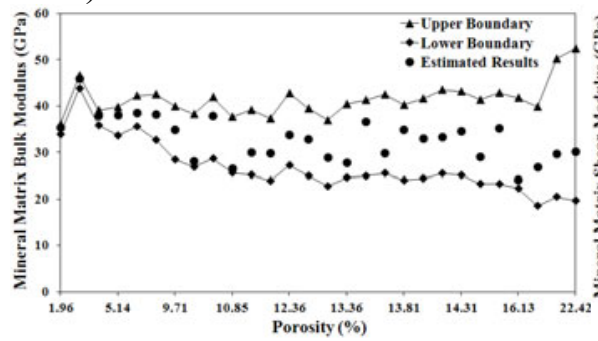

b)

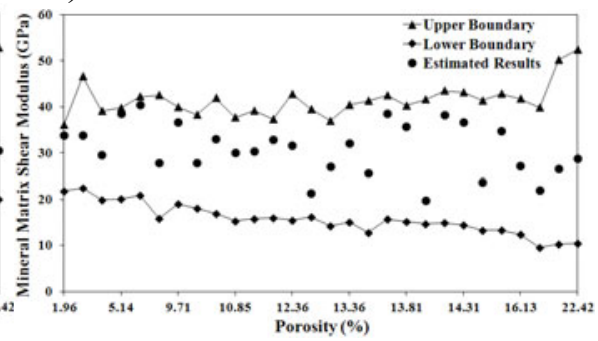

Fig. 4. Calculation results of upper and lower bounds for mineral moduli, and estimated results of these mineral moduli for 28 sandstone samples by this estimation method: (a) mineral matrix bulk modulus, (b) mineral matrix shear modulus. Triangle line is calculated upper boundary, diamond line is calculated lower boundary, and round dots are estimated results. 
a)

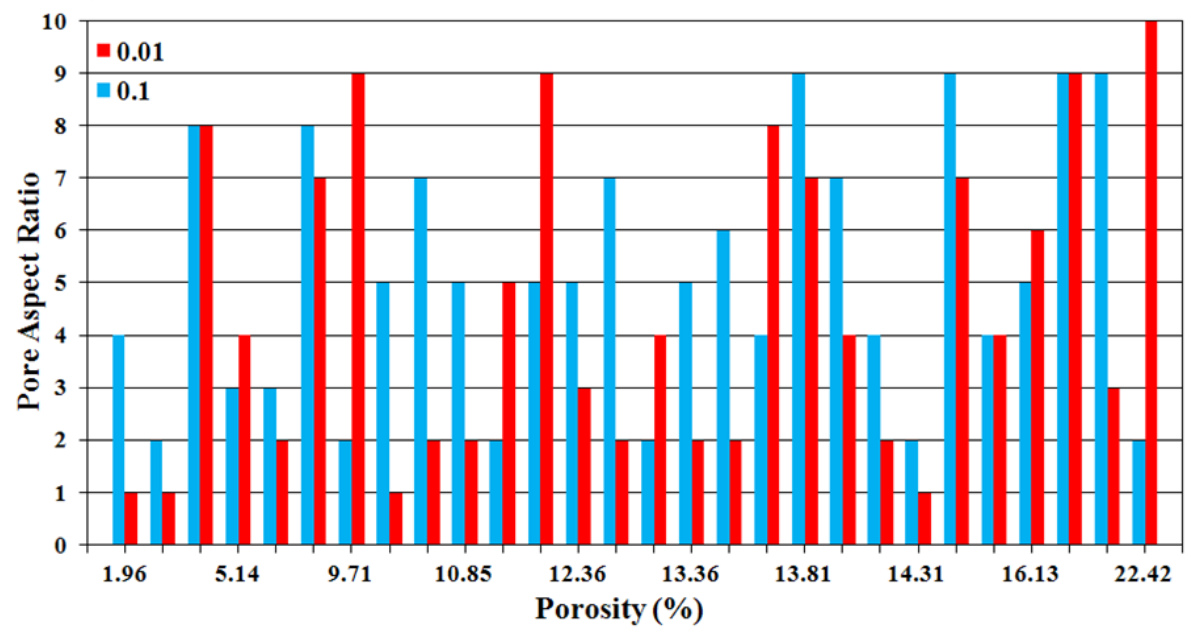

b)

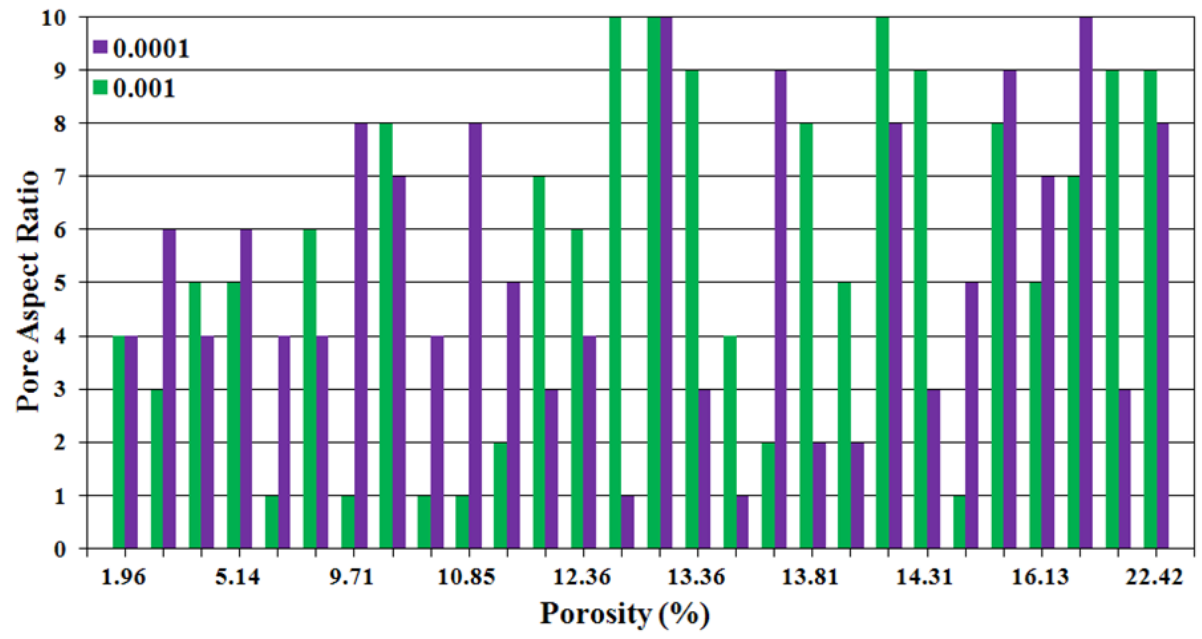

Fig. 5. The estimated results of pore aspect ratios of four different scales for 28 sandstone samples: (a) blue bar is estimated pore aspect ratio for $N_{1}$, red bar is estimated pore aspect ratio for $N_{2}$; (b) green bar is estimated pore aspect ratio for $N_{3}$, purple bar is estimated pore aspect ratio for $N_{4}$.

than $12.36 \%$ ), the estimated results of bulk moduli are from $24.1 \mathrm{GPa}$ to $36.6 \mathrm{GPa}$, and the estimated results of shear moduli are from $19.8 \mathrm{GPa}$ to $38.6 \mathrm{GPa}$. 
Figure 5 presents the estimated results of pore aspect ratios of four different scales for 28 sandstone samples. In Figure 5a, blue bar is for the estimated pore aspect ratio for $N_{1}$, red bar is for the estimated pore aspect ratio for $N_{2}$. In Figure 5b, green bar is for the estimated pore aspect ratio for $N_{3}$, and purple bar is for the estimated pore aspect ratio for $N_{4}$. Although

a)

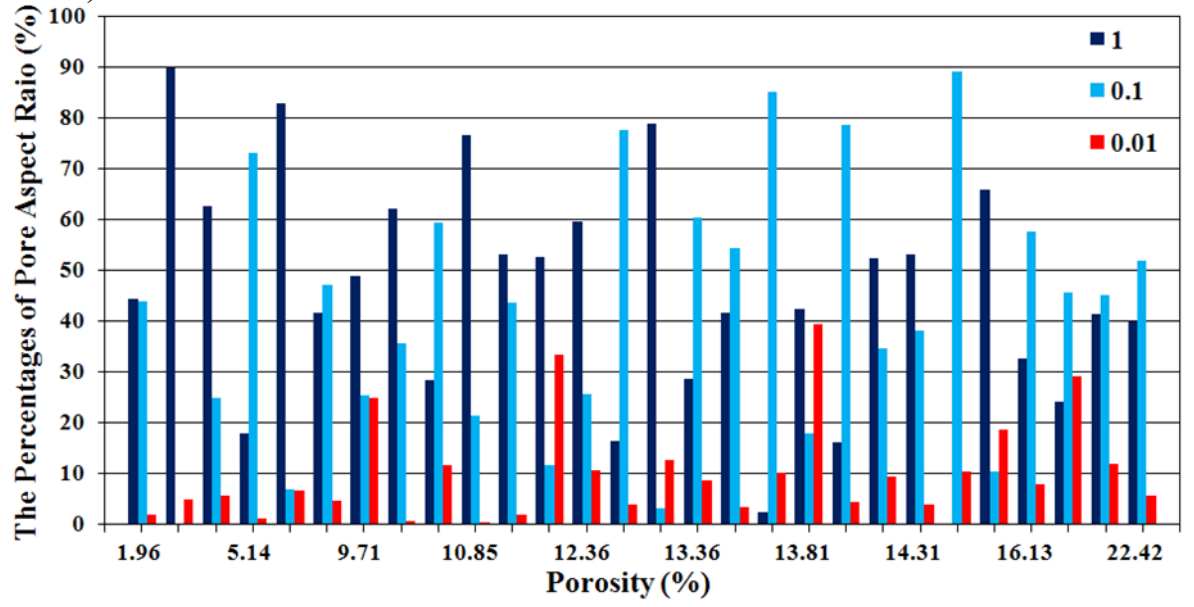

b)

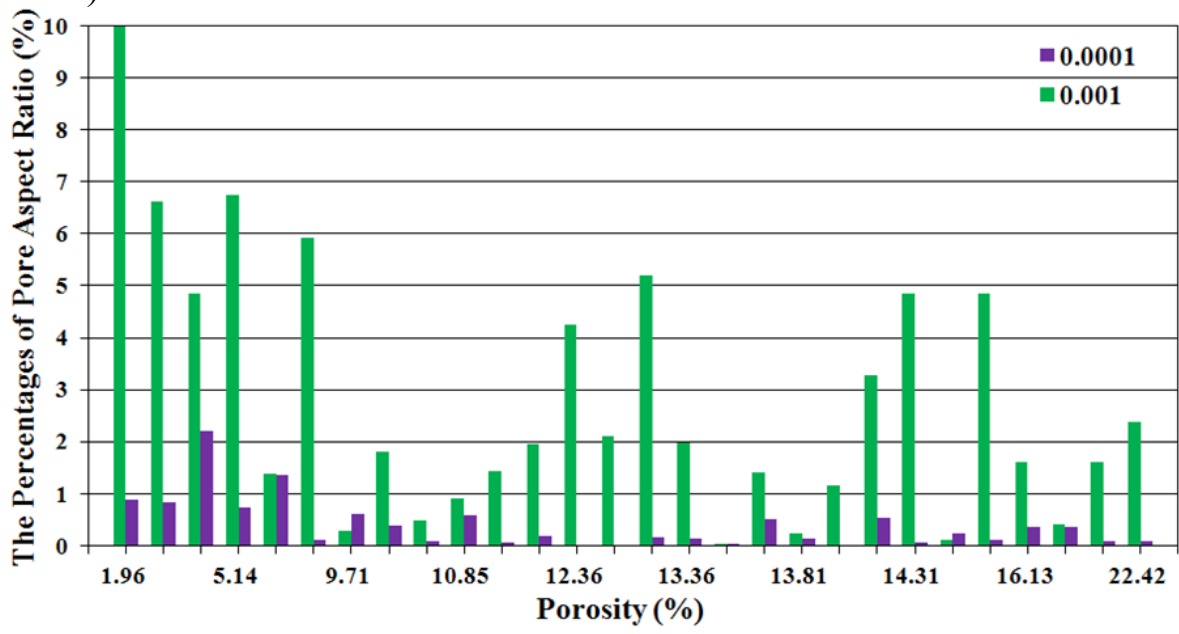

Fig. 6. The estimated results of the percentages of pore aspect ratios of five different scales for 28 sandstone samples: (a) dark blue bar is estimated percentages of pore aspect ratio for $\alpha=10^{\circ}$, blue bar is estimated percentages of pore aspect ratio for $\alpha=N_{1} \times 10^{-1}$, red bar is estimated percentages of pore aspect ratio for $\alpha=\mathrm{N}_{2} \times 10^{-2}$; (b) green bar is estimated percentages of pore aspect ratio for $\alpha=\mathrm{N}_{3} \times 10^{-3}$, purple bar is estimated percentages of pore aspect ratio for $\alpha=N_{4} \times 10^{-4}$. 
there is no significant feature for these estimated pore aspect ratios, it can be carefully seen from Fig. 5 that the estimated pore aspect ratios in intermediate-low porosity samples are a little smaller than those in intermediate-high porosity samples.

Figure 6 presents the estimated results of the percentages of pore aspect ratios of five different scales for 28 sandstone samples. In Fig. 6a, dark blue bar is for the estimated percentage of pore aspect ratio for $\alpha=10^{\circ}$, blue bar is for the estimated percentage of pore aspect ratio for $\alpha=N_{1} \times 10^{-1}$, red bar is for the estimated percentage of pore aspect ratio for $\alpha=N_{2} \times 10^{-2}$. In Fig. 6b, green bar is for the estimated percentage of the pore aspect ratio for $\alpha=$ $N_{3} \times 10^{-3}$, and purple bar is for the estimated percentages of pore aspect ratio for $\alpha=N_{4} \times 10^{-4}$.

It can be concluded from Fig. 6 that the spherical pores and the intergranular pores appear to be the dominant type in the sandstone samples. Per centages of the spherical pores in 12 samples are between $50 \%$ and $90 \%$, while percentages of the intergranular pores in 12 samples are between $50 \%$ and $89 \%$. Crack pores have the lowest percentages, especially for the percentages of crack pores with $\alpha=N_{3} \times 10^{-3}$ and $\alpha=N_{4} \times 10^{-4}$. The former are less than $10 \%$ and the latter are less than $2.2 \%$. It also can be learnt from Fig. $6 \mathrm{~b}$ that there are more crack pores in the 6 low porosity samples (porosity less than $9.71 \%$ ) than in the 15 intermediate-high porosity samples (porosity greater than $12.36 \%$ ).

Thus, in this sandstone reservoir, pore structures of sandstone can mainly be characterized by spherical pores and intergranular pores; although the usage of the crack pores has a very low probability, they should not be neglected, especially in the low porosity sandstone samples.

\section{FLUID SUBSTITUTION TESTING AND DISCUSSION}

In order to test reliability and accuracy of the estimated parameters by this estimation method, we put estimated parameters (mineral moduli and pore aspect ratios spectrum of 28 samples) into KT model, change the fluid from water to oil saturated condition, and calculate P-wave and S-wave velocities of these sandstone samples, then compare calculation results with measured data and also calculate relative errors between the KT fluid substitution results and measured data. In the fluid substitution process, bulk modulus and shear modulus of the fluid inclusion are $1.35 \mathrm{GPa}$ and $0 \mathrm{GPa}$, respectively.

Figure $7 \mathrm{a}$ is a comparison of theoretical data and measured data for oil saturated $\mathrm{P}$-wave velocity. The theoretical data and measured data match very well for the 13 samples with intermediate-low porosity. The triangle dots (measured data) and round dots (theoretical data) are overlapped in 12 samples. And for the 15 samples with intermediate-high porosity, triangle 
a)

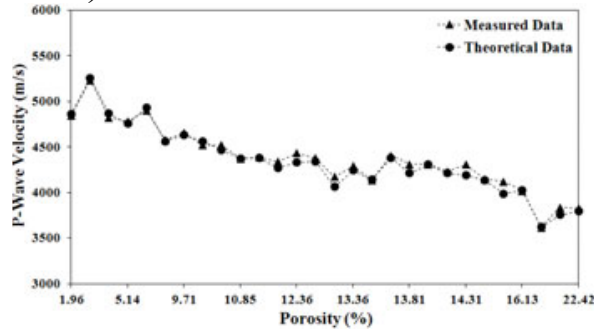

b)

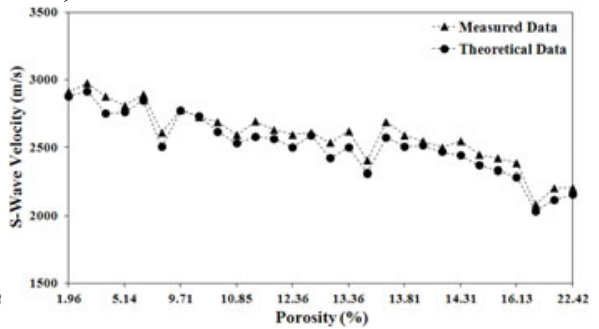

Fig. 7. Comparison between theoretical data (KT fluid substitution results) and measured data for 28 sandstone samples: (a) oil saturated P-wave velocity, (b) oil saturated S-wave velocity. Triangle dash line is measured data, round dash line is theoretical data.

dots and round dots coincide in 11 samples. These excellent data matches demonstrate that the estimation results by this new estimation method are reliable and accurate.

Figure $7 \mathrm{~b}$ is a comparison of theoretical data and measured data for oil saturated S-wave velocity. Comparing Fig. $7 \mathrm{~b}$ with $7 \mathrm{a}$ shows that the fitting of S-wave velocity is not as good as that of P-wave velocity. For the 13 samples of intermediate-low porosity, triangle dots and round dots are overlapped in 5 samples. For the 15 samples with intermediate-high porosity, triangle dots and round dots have excellent matches in 5 samples. But it doesn't mean the KT fluid substitution results for oil saturated S-wave velocity have poor fitting with the measured data. We also calculate the relative errors between KT fluid substitution results and measured data:

$$
\begin{gathered}
R_{1}=\frac{\left|K_{o i l}^{o b s}-K_{o i l}^{K T}\right|}{K_{o i l}^{o b s}} \\
R_{2}=\frac{\left|\mu_{o i l}^{o b s}-\mu_{o i l}^{K T}\right|}{\mu_{o i l}^{o b s}}
\end{gathered}
$$

where $R_{1}$ is the calculated relative error for mineral matrix bulk moduli while $R_{2}$ is the calculated relative error for mineral matrix shear moduli. $K_{o i l}^{o b s}$ and $\mu_{o i l}^{o b s}$ are bulk moduli and shear moduli of oil saturated data, respectively, of the measured results. $K_{o i l}^{K T}$ and $\mu_{\text {oil }}^{K T}$ are bulk moduli and shear moduli of oil saturated data, respectively, of the KT model fluid substitution calculation results. 
Figure 7 shows relative errors between theoretical data (KT fluid substitution results) and measured data. It shows that the relative errors of both Pwave velocities and S-wave velocities of 28 sandstone samples are all less than $5 \%$. It indicates that the estimated mineral moduli and pore aspect ratios spectrum are accurate by this new estimation method. Except for only 2 samples, the relative errors of P-wave velocities are smaller than those of Swave velocities in most 26 sandstone samples. It demonstrates that the estimated results are more appropriate for predicting P-wave rock velocity.

\section{CONCLUSIONS}

This paper presents a new method for estimation of pore structure and mineral moduli based on KT model and Biot's coefficient. The new approach chooses pore aspect ratios of five different scales in KT model to construct pore structure of a sandstone reservoir. This avoids the disadvantages in previous studies that consider only one or few pore shapes to simulate pore structure in sandstone. The Biot's coefficient makes full use of relationships between different rock elastic moduli. It can properly determine upper and lower bounds of mineral elastic moduli when only log data are available.

This new estimation method of rock physics parameters can be applied directly to estimation of pore aspect ratios spectrum and mineral matrix moduli, which can help researchers better understand quantitative and nonlinear relations between different rock elastic moduli. The rock parameters estimated by the estimation method not only can perform fluid substitution and velocity prediction, but also can build mathematical physics relations between rock physics parameters (porosity, density, saturation, fluid type, pore shape) and seismic attributes (P-wave velocity, S-wave velocity, wave impedance, amplitude, AVO response).

Acknowledgements. This work was supported by the Key National Projects of Science and Technology of China (2011ZX05019-008-09) and the National Natural Science Foundation of China (41304115).

\section{Appendix}

\section{Details of coefficient equations in KT model}

We list the coefficient equations of $P^{m i}$ and $Q^{m i}$ in KT model which are described by Kuster and Toksöz (1974) 


$$
\begin{gathered}
P^{m i}=\frac{1}{3} T_{i j j j} \\
Q^{m i}=\frac{1}{5}\left(T_{i j j j}-\frac{1}{3} T_{i j j j}\right)
\end{gathered}
$$

The scalars $T_{i j i j}$ and $T_{i i j j}$ which are used in this study are given by

$$
\begin{gathered}
T_{i i j j}=\frac{3 F_{1}}{F_{2}} \\
T_{i j i j}-\frac{1}{3} T_{i i j j}=\frac{2}{F_{3}}+\frac{1}{F_{4}}+\frac{F_{4} F_{5}+F_{6} F_{7}-F_{8} F_{9}}{F_{2} F_{4}}
\end{gathered}
$$

where

$$
\begin{gathered}
F_{1}=1+A\left[\frac{3}{2}(g+\theta)-R\left(\frac{3}{2} g+\theta-\frac{4}{3}\right)\right] \\
F_{2}=1+A\left[1+\frac{3}{2}(g+\theta)-\frac{R}{2}(3 g+5 \theta)\right]+B(3-4 R) \\
+\frac{A}{2}(A+3 B)(3-4 R)\left[g+\theta-R\left(g-\theta+2 \theta^{2}\right)\right] \\
F_{3}=1+\frac{A}{2}\left[R(2-\theta)+\frac{1+\alpha^{2}}{\alpha^{2}} g(R-1)\right] \\
F_{4}=1+\frac{A}{4}[3 \theta+g-R(g-\theta)] \\
F_{5}=A\left[R\left(g+\theta-\frac{4}{3}\right)-g\right]+B \theta(3-4 R) \\
F_{6}=1+A[1+g-R(g+\theta)]+B(1-\theta)(3-4 R) \\
F_{7}=2+\frac{A}{4}[9 \theta+3 g-R(5 \theta+3 g)]+B \theta(3-4 R) \\
F_{8}=A\left[1-2 R+\frac{g}{2}(R-1)+\frac{\theta}{2}(5 R-3)\right]+B(1-\theta)(3-4 R) \\
F_{9}=A[g(R-1)-R \theta]+B \theta(3-4 R)
\end{gathered}
$$

Then

$$
A=\left(\mu_{i} / \mu_{m a}-1\right)
$$




$$
\begin{gathered}
B=\left[\left(K_{i} / K_{m a}\right)-\left(\mu_{i} / \mu_{m a}\right)\right] / 3 \\
R=3 \mu_{m a} /\left(3 K_{m a}+4 \mu_{m a}\right) \\
g=\alpha^{2}(3 \theta-2) /\left(1-\alpha^{2}\right) \\
\theta=\frac{\alpha^{2}}{\left(1-\alpha^{2}\right)^{3 / 2}}\left[\cos ^{-1} \alpha-\alpha\left(1-\alpha^{2}\right)^{1 / 2}\right]
\end{gathered}
$$

\section{References}

Ament, W. (1953), Sound propagation in gross mixtures, J. Acoustic Soc. Am. 25, 638-641, DOI: 10.1121/1.1907156.

Anselmetti, F., and G.P. Eberli (1999), The velocity-deviation log: A tool to predict pore type and permeability trends in carbonate drill holes from sonic and porosity or density logs, AAPG Bull. 83, 3, 450-466.

Bakhorji, A., H. Mustafa, S. Aramco, and P. Avseth (2012), Rock physics modeling and analysis of elastic signatures for intermediate to low porosity. In: $82 n d$ Annual International Meeting, SEG, Technical program expanded abstracts, $1-5$.

Berryman, J. (1980), Long-wavelength propagation in composite elastic media, $J$. Acoust. Soc. Am. 68, 1809-1831.

Berryman, J. (1995), Mixture theories for rock properties. In: T.J. Ahrens (ed.), Rock Physics and Phase Relations: A Handbook of Physical Constants, American Geophysical Union, Washington, D.C., 205-228, DOI: 10.1029/ RF003p0205.

Budiansky, B. (1965), On the elastic moduli of some heterogeneous materials, Mech. Phys. Solids 13, 4, 223-227, DOI: 10.1016/0022-5096(65)90011-6.

Cleary, C., G. Coates, and J. Dumanoir (1984), Theoretical and experimental bases for the dual-water model for interpertation of shaley sands, Soc. Petrol. Eng. J. 24, 153-168, DOI: 10.2118/6859-PA.

Eshelby, J. (1957), The determination of the elastic field of an ellipsoidal inclusion, and related problems, Proc. Roy. Soc. London A241, 1226, 376-396, DOI: 10.1098/rspa.1957.0133.

Gassmann, F. (1951), Elastic waves through a packing of spheres, Geophysics 16, 4, 673-682, DOI: 10.1190/1.1437718.

Hadley, K. (1975), Comparison of calculated and observed crack densities and seismic velocities in westerly granite, J. Geophys. Res. 81, 20, 3484-3494, DOI: 10.1029/JB081i020p03484. 
Hashin, Z., and S. Shtrikman (1963), A variational approach to the elastic behavior of multiphase materials, Mech. Phys. Solids 11, 2, 127-140, DOI: 10.1016/ 0022-5096(63)90060-7.

Hill, R. (1952), The elastic behavior of crystalline aggregate, Proc Phys. Soc. 65, 389, 349-354, DOI: 10.1088/0370-1298/65/5/307.

Hill, R. (1965), A self-consistent mechanics of composite materials, Mech. Phys. Solids 13, 4, 213-222, DOI: 10.1016/0022-5096(65)90010-4.

Jensen, E.H., C.F. Andersen, and T.A. Johansen (2011), Estimation of elastic moduli of mixed porous clay composites, Geophysics 76, 1, 9-20, DOI: 10.1190/ 1.3511351 .

Johansen, T.A., E.H. Jensen, G. Mavko, and J. Dvorkin (2013), Estimate rock physics modeling for reservoir quality prediction, Geophysics 78, 2, 1-18, DOI: 10.1190/geo2012-0215.1.

Krief, M., J. Garat, J. Stellingwerff, and J. Ventre (1990), A petrophysical interpretation using the velocities of $\mathrm{P}$ and $\mathrm{S}$ waves (full-waveform sonic), The Log Analyst 31, 6, 355-369.

Kuster, G., and M. Toksöz (1974), Velocity and attenuation of seismic waves in two-phase media: Part 1 - Theoretical formulations, Geophysics 39, 5, 587606, DOI: 10.1190/1.1440450.

Lin, K., X.J. Xiong, X. Yang, Z.H. He, J.X. Cao, Z.X. Zhang, and P. Wang (2011), Self-adapting extraction of matrix mineral bulk moduli and verification of fluid substitution, Appl. Geophys. 8, 2, 110-116, DOI: 10.1007/s11770-0110278-0.

Markov, M., E. Kazatchenko, A. Mousatov, and E. Pervago (2013), Novel approach for simulating the elastic properties of porous rocks including the critical porosity phenomena, Geophysics 78, 4, L37-L44, DOI: 10.1190/geo20120260.1.

Mavko, G., and N. Saxena (2013), Embedded-bound method for estimating the change in bulk moduli under either fluid or solid substitution, Geophysics 78, 5, L87-L99, DOI: 10.1190/geo2013-0074.1.

Mavko, G., T. Mukerji, and J. Dvorkin (1998) The Rock Physics Handbook, Cambridge University Press, Cambridge.

Metropolis, N., A.W. Rosenbluth, M.N. Rosenbluth, A.H. Teller, and E. Teller (1953), Equation of state calculations by fast computing machines, J. Chem. Phys. 21, 1087-1092, DOI: 10.1063/1.1699114.

Mori, T., and K. Tanaka (1973), Average stress in matrix and average elastic energy of materials with misfitting inclusions, Acta Metall. 21, 5, 571-574, DOI: 10.1016/0001-6160(73)90064-3.

Norris, A., P. Sheng, and A. Callegari (1985), Effective-medium theories for twophase dielectric media, Appl Phys. 57, 6, 1990-1996, DOI: 10.1063/ 1.334384 . 
Nur, A., G. Mavko, and J. Dvorkin (1998), Critical porosity: The key to relating physical properties to porosity in rocks, The Leading Edge 17, 357-362, DOI: $10.1190 / 1.1887540$.

O’Connell, R., and B. Budiansky (1974), Seismic velocities in dry and saturated cracked solids, J. Geophys. Res. 79, 35, 5412-5426, DOI: 10.1029/ JB079i035p05412.

Raymer, L.L., E.R. Hunt, and J.S. Gardner (1980), An improved sonic transit timeto-porosity transform. In: 21st Ann. Logg. Symp., SPWLA.

Saleh, A., and J.P. Castagna (2004), Revisiting the Wyllie time average equation in the case of near spherical pores, Geophysics 69, 1, 45-55, DOI: 10.1190/ 1.1649374 .

Sprunt, F., and W. Brace (1974), Direct observations of microcavities in crystalline rocks, Int. J. Rock Mech. Min. Sci. Geomech. Abstr. 11, 4, 139-150, DOI: 10.1016/0148-9062(74)92874-5.

Timur, A., W. Hempkins, and R. Weinbrandt (1971), Scanning electron microscope study of pore systems in rocks, Geophysics 76, 20, 4932-4948, DOI: 10.1029/JB076i020p04932.

Toksöz, M., C.H. Cheng, and A. Timur (1976), Velocities of seismic waves in porous rocks, Geophysics 41, 4, 621-645, DOI: 10.1190/1.1440639.

Tran, D.T., and S. Chandra (2008), Changes in crack aspect-ratio concentration from heat treatment: A comparison between velocity estimation and experimental data, Geophysics 73, 123-132.

Vernik, L., and M. Kachanov (2010), Modeling elastic properties of siliciclastic rocks, Geophysics 75, 6, E171-E182, DOI: 10.1190/1.3494031.

Walsh, J. (1965), The effect of cracks on the compressibility of rock, J. Geophys. Res. 70, 2, 381-389, DOI: 10.1029/JZ070i002p00381.

Wang, Z.J. (2001), Fundamentals of seismic rock physics, Geophysics 66, 2, 398412, DOI: $10.1190 / 1.1444931$.

Wu, T. (1966), The effect of inclusion shape on the elastic moduli of a two phase material, Int. J. Solids Struct. 2, 1, 1-8, DOI: 10.1016/0020-7683(66)900023.

Zimmerman, R. (1991), Compressibility of Sandstones, Elsevier, New York.

Zimmerman, R. (1984), The elastic moduli of a solid with spherical pores: New selfconsistent method, Int. J. Rock Mech. Min. Sci. Geomech. Abstr. 21, 6, 339343, DOI: 10.1016/0148-9062(84)90366-8.

Received 19 November 2015 Received in revised form 17 April 2016 Accepted 15 June 2016 